\section{Clear cell renal cell carcinoma with vaginal and brain metastases: a case report and literature review}

\author{
Tobe Momah, 'Etwaru Dhanan, \\ Phillip Xiao, ${ }^{3}$ Vasantha Kondamudi' \\ 'PGY-II Department of Family Medicine; \\ ${ }^{2}$ Department of Urology; ${ }^{3}$ Department of \\ Pathology; Brooklyn Hospital Center, \\ Brooklyn, New York, NY, USA
}

\begin{abstract}
There are very few cases of clear cell renal cell carcinoma with metastases to the vagina and brain reported in the literature. Our case study highlights this rare clinical occurrence and its associated complications including pulmonary embolism. In addition we discuss current management guidelines for treating and diagnosing the disease, and how this management improves prognosis.
\end{abstract}

\section{Case Report}

\section{Presentation and history}

A 55-year-old African American female with a past medical history of hypertension, nicotine dependence (stopped smoking eleven years ago), and Para 2022 (status post-right salpingectomy for ectopic pregnancy) presented with six weeks of persistent postmenopausal bleeding per vagina (PV). Prior to presentation the patient had been menopausal for ten years and used only amlodipine and avalide tablets as medications. She has a positive family history (sister) of breast cancer and denied intra-partum exposure to diethyl stilbesterol (DES). The physical examination revealed a loose necrotic mass with a pedunculated polyp attached to the posterior wall of the vagina and measuring $3.5 \times 1.5 \times 1 \mathrm{~cm}$. Endocervical and endometrial curetting were negative for malignancy while polypectomy of the vaginal mass revealed foci of necrosis, surface ulceration, and a polypoid tumor consistent with clear cell carcinoma of the vagina (Figure 1).

\section{Initial management}

A computerized tomography (CT) scan of the abdomen with contrast had been done four months previously and showed a $4.4 \mathrm{~cm}$ left kidney mass with peripheral enhancement. A CT scan of the chest, abdomen, and pelvis done after the diagnosis of clear cell malignancy revealed a pulmonary embolism (PE) in the left lower lobe pulmonary arteries, an enlarged area of enhancement measuring $7 \mathrm{~cm}$ in the inferior aspect of the left kidney (Figure 2), and a $6 \times 5.6 \mathrm{~cm}$ focus of soft tissue enhancement in the region of the vagina (Figure 3). These findings were suggestive of cystic renal cell carcinoma and metastatic clear cell carcinoma of the vagina, respectively.

\section{Treatment}

The patient was started on Lovenox (enoxaparin) and coumadin, but she started bleeding PV a week later and was admitted to our inpatient service with shortness of breath, and for anticoagulation treatment and inferior vena cava filter placement. She later underwent a laparoscopic hand-assisted left nephrectomy with histopathological examination of the $6.6 \times 6 \times 4.5 \mathrm{~cm}$ left lower kidney pole specimen, which was consistent with renal clear cell carcinoma (Figure 4). The tumor extended into the left perirenal adipose tissue, was a Fuhrman nuclear grade G3 tumor, involved the left renal vein, and was staged as T3bN0Mx secondary to the vaginal metastases.

\section{Clinical course and outcome}

The patient tolerated surgery well, and after discharge received palliative radiation therapy (4860 cGy in 27 fractions of 180 cGy) to the pelvis. However, she was re-admitted three months after discharge for persistent headaches and right-sided upper extremity numbness and weakness, which on CT of the head was found to be because of a secondary left posterior parietal mass. She underwent an intracranial incision biopsy of the left parietal brain tumor that showed metastatic clear cell carcinoma histologically, consistent with a renal primary tumor. She received postoperative therapeutic irradiation of the cranium for metastatic brain lesions and recently was started on chemotherapy (Sutent $50 \mathrm{mg}$ once daily orally). She continues taking her antihypertensive medication but had to discontinue her anticoagulation drugs because of recurrent PV bleeding. She currently has good performance status and otherwise is stable medically.

\section{Discussion}

\section{Epidemiology}

Clear cell renal cell carcinoma (RCC) is the most common primary site for clear cell tumors, yet clear cell RCC metastases to the vagina or brain are rare with only one case of the former reported in the literature to date. ${ }^{1}$ Eighty cases of RCC with vaginal metastases have been reported in the literature, ${ }^{2}$ and because clear cell carcinomas constitute about $80 \%$ of all renal cell carcinomas, ${ }^{2}$ most of these cases may be clear cell carcinomas in fact, but are under-reported as such. Clear cell RCC
Correspondence: Tobe Momah, PGY-II Department of Family Medicine, Brooklyn Hospital Center, 121 Dekalb Avenue, Brooklyn, New York, NY 11201, USA. E-mail: tobemomah@yahoo.com

Key words: renal cell carcinoma, clear cell, metastases.

Conflict of interest: the authors report no conflicts of interest.

Received for publication: 18 June 2009.

Revision received: 24 September 2009.

Accepted for publication: 1 October 2009.

This work is licensed under a Creative Commons Attribution 3.0 License (by-nc 3.0).

CC Copyright T. Momah et al., 2009

Licensee PAGEPress, Italy

Hematology Reviews 2009; 1:e16

doi:10.4081/hr.2009.e16

usually occurs in the sixth or seventh decade of life and is three times more common in men than in women. ${ }^{2}$

\section{Clinical presentation}

The most common symptom on presentation in RCC cases with vaginal metastases is vaginal bleeding, ${ }^{1,2}$ and its most common sites for metastases include extra-renal regions like lung, lymph nodes, liver, and bones. ${ }^{1}$ Our case was unique for its metastatic sites, clinical presentation, and associated complications. Clear cell RCC with metastases to the vagina and brain is very uncommon with one case of the former ${ }^{1}$ and none of the latter reported in the literature. In postmenopausal women only one case of primary clear cell carcinoma of the vagina has been reported ${ }^{3}$ because these tumors tend to occur more in young patients exposed to DES in utero. ${ }^{4}$ Therefore, a solitary lesion of clear cell carcinoma in the vagina in a postmenopausal patient is more likely to be a metastatic secondary than a primary lesion, and a consideration of clear cell tumor primary sites should be performed immediately. This was done in our case and revealed a primary site in the left kidney, which is typically the primary site for clear cell RCC as the retrograde filling of the left renal vein from the left ovarian vein and uterovaginal plexus eventually involves the left kidney. ${ }^{5}$

\section{Complications}

The vascular effects of clear cell RCC include the intravascular growth of the tumor into the left renal vein, and may have caused the tumor emboli to the left lower lung pulmonary arteries that resulted in our patient's pulmonary emboli. The vascular involvements of clear cell carcinoma are well documented in the literature ${ }^{6}$ but this is the first reported case with an associated pulmonary embolism. 


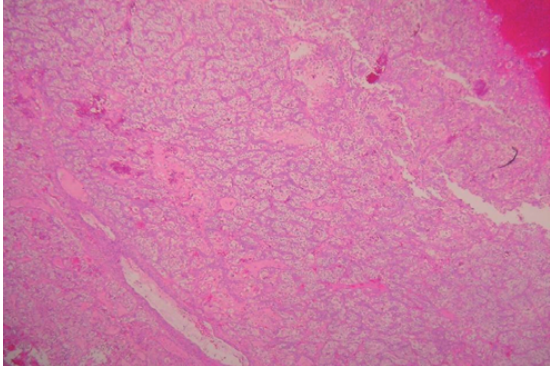

Figure 1. Vaginal metastases from renal cell carcinoma, clear cell type. Microscopic examination of the tumor from the vagina reveals the compact alveolar architecture of cells with clear cytoplasm and distinct cell boundaries in a background of delicate vasculature. (H\&E stain; magnification 100X.)

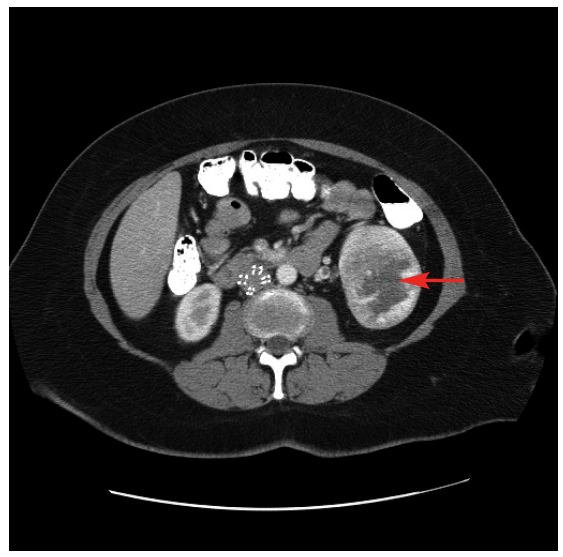

Figure 2. Computerized tomography scan of the abdomen showing a $7 \mathrm{~cm}$ area of enhancement in the left lower pole of the kidney (arrow) consistent with renal clear cell carcinoma.

\section{Diagnostic methods}

Fine needle aspiration cytology to establish the anatomic site of origin in metastatic clear cell RCC cases, when combined with clinical features, ${ }^{7}$ is $95 \%$ accurate and is easier to administer in outpatient settings and followup cases than are endometrial biopsies. However, the use of magnetic resonance imaging (MRI) and CT scans still provide the mainstay of primary clear cell RCC diagnoses (and subsequent diagnoses of secondary metastases) owing to their greater utility and accuracy.

\section{Treatment}

The use of whole body radiation therapy in cases involving a solitary metastatic site clear cell carcinoma currently is not recommended

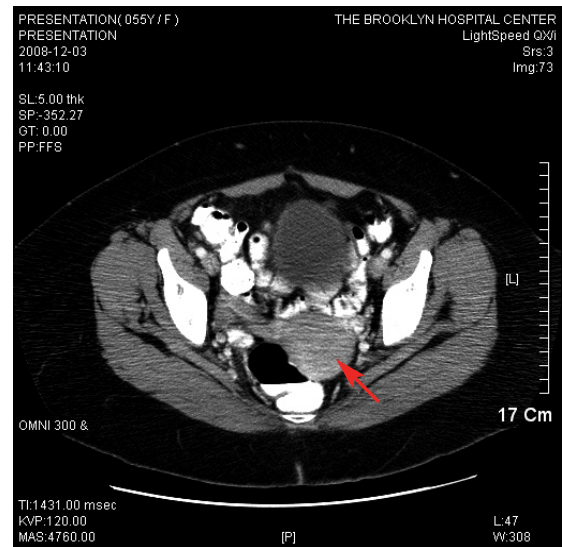

Figure 3. Computerized tomography scan of the pelvis showing soft tissue enhancement measuring $6 \times 5.6 \mathrm{~cm}$ in the left wall of the vagina (arrow) consistent with metastatic clear cell carcinoma of the vagina.

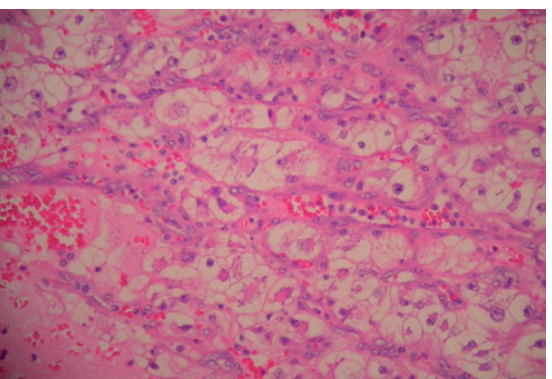

Figure 4. Renal cell carcinoma, clear cell type. Microscopic examination of the kidney tumor shows alveolar architecture of the cells with clear cytoplasm and distinct cell boundaries in a background of delicate vasculature. (H\&E stain; magnification 400X.)

as adjuvant loco-regional radiation therapy is the preferred treatment for clear cell RCC. ${ }^{8}$ In diffuse or non-resectable disease, or when paraneoplastic syndrome, severe hemorrhage, or severe pain is present, however, the use of palliative nephrectomy is recommended. ${ }^{9}$

\section{Prognosis}

Multiple metastases, recurrent metastases, and renal vein involvements are poor prognostic indicators for survival ${ }^{10}$ and, as seen in our patient, are prone to develop complications like pulmonary embolism. Patients with multifocal clear cell RCC (like our patient with two metastatic sites) are more likely to have a contralateral recurrence than are patients with solitary clear cell RCC (risk ratio: 2.91, $p=0.142) .{ }^{11}$

\section{Conclusions}

The development of recurrent shortness of breadth in a clear cell RCC patient with vaginal metastases is indicative of pulmonary embolism, and the presence of neurological deficits is suggestive of brain metastases. A high indicative index for a clear cell primary tumor is a requirement for the diagnosis of a secondary clear cell vaginal malignancy and for avoiding complications like pulmonary embolism, further metastatic spread, and the consequent deterioration of the patient.

\section{References}

1. Queiroz C, Bacchi C, Oliveira C, et al. Cytologic diagnosis of vaginal metastases from renal cell carcinoma. A case report. Acta Cytol 1999;43:1098-100.

2. Boggess M, Hester O, Srcher S. Renal clear cell carcinoma appearing as a left neck mass. Cytopathology 1991;2:47-8.

3. Hughes J, Jensen C, Donnelly A, et al. The role of fine-needle aspiration cytology in the evaluation of metastatic clear cell tumors. Cancer Cytopathol 1999;87:380-9.

4. Watanabe Y, Ueda $H$, Nozaki $K$, et al. Advanced primary clear cell carcinoma of the vagina not associated with diethylstilbestrol. Acta Cytol 2002;46:577-81.

5. Matias-Guiu X, Lerma E, Prat J. Clear cell tumors of the female genital tract. Semin Diagn Pathol 1997;14:233-9.

6. Papac R, Poo-Hwu W. Renal cell carcinoma: a paradigm of lanthanic disease. Am J Clin Oncol 1999;22:223-31.

7. Allard J, McBroom J, Zahn C, et al. Vaginal metastases and thrombocytopenia from renal cell carcinoma. Gynecol Oncol 2004; 92:970-3.

8. Greenberg R, Charles R, Samana A, et al. Surgical management of recurrent genitourinary malignancies. Semin Oncol 1993;20:473-92.

9. Walsh P, Retik A, Vaughan E, et al., editors. Campbell's Urology. 8th edn. Philadelphia: Saunders, 2002, pp 2714-9.

10. McNichols D, Segura J, DeWeerd J. Renal cell carcinoma: long term survival and late recurrence. J Urol 1981;126:17-23.

11. Dimarco D, Lohse C, Zincke H, et al. Long term survival of patients with unilateral sporadic multifocal renal cell carcinoma according to histologic subtype compared to patients with solitary tumors after radical nephrectomy. Urology 2004;64:462-7. 